\title{
COMUNICAÇÃO, MARKETING E RESPONSABILIDADE SOCIAL: O CASO NATURA
}

\section{Communication, Marketing and Social Responsibility: the case Natura}

\section{Comunicación, marketing y responsabilid social: el caso Natura}

\author{
José Américo Tristão ${ }^{1}$ \\ Virgínia Talaveira Valentini Tristão ${ }^{2}$ \\ Elias Frederico ${ }^{3}$ \\ Agustin Rodrigues ${ }^{4}$
}

\section{Resumo}

Este trabalho examina as práticas de marketing e responsabilidade social desenvolvidas pela Natura S.A., empresa de capital aberto, com atuação na área de cosméticos e saúde, apontada pelo Instituto Ethos de Empresas e Responsabilidade Social, por seis anos consecutivos, como destaque por sua atuação social. Para alcançar o objetivo proposto, foi realizada uma pesquisa bibliográfica sobre o embasamento teórico dos conceitos de marketing e responsabilidade social, e elaborado um estudo de caso da empresa, tendo, como objeto, as práticas corporativas voltadas para o atendimento de demandas sociais por ética e responsabilidade social dos seus principais stakeholders. Como fonte de dados foram utilizados os Balanços Sociais referentes ao período de 2000 a 2005 e entrevistas efetuadas com diretores e gerentes da empresa. Os resultados da análise do conteúdo documental e das entrevistas demonstram haver relação entre as demandas dos stakeholders e a modificação do comportamento empresarial, sugerindo que a empresa leva em consideração aspectos do marketing social na sua gestão. Os resultados ainda indicam que a qualidade das relações mantidas com os stakeholders contribui para o desenvolvimento da cidadania, destacando-se a atuação e orientação da empresa para práticas de Responsabilidade Social em razão da existência de uma cultura corporativa orientada ao mercado e voltada à qualidade de relacionamentos com

\footnotetext{
${ }^{1}$ Doutor em Administração de Empresas pela FGV-EAESP. Professor do Departamento de Administração da PUC-SP.tristao@gvmail.br.

${ }^{2}$ Doutora em Educação pela USP. Mestre em Administração Pública e Governo pela FGV-EAESP. Professora da PUC-SP. vtalaveira@gmail.com.

${ }^{3}$ Doutor em Administração de Empresas pela FGV-EAESP. Professor da EACH-USP. elias.frede@ gmail.com.

${ }^{4}$ Doutor em Comunicação e Semiótica e Mestre em Administração pela PUC-SP. Professor de Marketing da PUC-SP. agustin@pucsp.br.
} 
Comunicação, marketing e responsabilidade social: o caso Natura

de José Américo Tristão, Virgínia Talaveira Valentini Tristão, Elias Frederico e Augustin Rodrigues

os stakeholders, ao desenvolvimento de ações e programas endereçados ao atendimento de necessidades tanto de clientes internos, os colaboradores da empresa, quanto externos, clientes e outros públicos interessados.

Palavras-chave: comunicação, marketing, responsabilidade social, Natura.

\section{Abstract}

This paper examines the marketing practices and social responsibility developed by Natura SA, a publicly traded company, with operations in the area of cosmetics and health, appointed by the Ethos Institute of Business and Social Responsibility, for six consecutive years, as highlighted by its social. To achieve the proposed objective, a literature search was performed on the theoretical concepts of marketing and social responsibility, and prepared a case study of the company, having as object, corporate practices aimed at meeting demands for social and ethical social responsibility of its key stakeholders. As a data source we used the Social Balances for the period 2000 to 2005 and conducted interviews with directors and managers of the company. The results of content analysis of documents and interviews show a relation between the demands of stakeholders and behavior modification business, suggesting that the company takes into account aspects of social marketing in its management. The results also indicate that the quality of the relationship with stakeholders contributes to the development of citizenship, highlighting the company's performance and guidance for Social Responsibility practices due to the existence of a market-oriented corporate culture and focused on quality relationships with stakeholders, developing activities and programs addressed to meet the needs of both internal customers, company employees, and external customers and other stakeholders.

Keywords: communication, marketing, social responsibility, Natura.

\section{Resumen}

Este artículo examina las prácticas de comercialización y la responsabilidad social desarrolladas por Natura SA, una compañía que cotiza en bolsa, con operaciones en el área de la cosmética y la salud, designado por el Instituto Ethos de Empresas y Responsabilidad Social, durante seis años consecutivos, como la más destacada en su dimensión social . Para lograr el objetivo propuesto, una búsqueda de la literatura se realizó en los conceptos teóricos del marketing y la responsabilidad social, y se preparó un estudio de caso de la empresa, que tiene como objeto, las prácticas empresariales orientados a satisfacer las demandas de ética y 
Comunicação, marketing e responsabilidade social: o caso Natura

de José Américo Tristão, Virgínia Talaveira Valentini Tristão, Elias Frederico e Augustin Rodrigues

social responsabilidad social de sus grupos clave de interés. Como fuente de datos se utilizaron los saldos Sociales para el período de 2000 a 2005 y llevó a cabo entrevistas con los directores y gerentes de la empresa. Los resultados del análisis de contenido de documentos y entrevistas muestran una relación entre las demandas de las partes interesadas y las empresas de modificación de conducta, lo que sugiere que la empresa tiene en cuenta aspectos de marketing social en su gestión. Los resultados también indican que la calidad de la relación con las partes interesadas contribuye al desarrollo de la ciudadanía, destacando el desempeño de la compañía y la guía para las prácticas de Responsabilidad Social debido a la existencia de una cultura corporativa orientada al mercado y centrada en la calidad las relaciones con los grupos de interés, actividades y programas de desarrollo dirigido a satisfacer las necesidades tanto de los clientes internos, los empleados de la empresa y los clientes externos y otras partes interesadas.

Palabras-clave: comunicación, marketing, responsabilidad social, Natura.

\section{INTRODUÇÃO}

A Responsabilidade Social ou Socioambiental Empresarial é um tema de crescente interesse nos mais diversos segmentos da sociedade, como: a mídia, o empresariado, a academia, o governo e a sociedade civil de um modo geral; e envolve medidas voltadas à prática de uma gestão empresarial transparente e ética, bem como a inserção de preocupações sociais e ambientais nas decisões corporativas. A Responsabilidade Social diz respeito à maneira como as empresas agem, como impactam e como se relacionam com o meio ambiente e suas partes legitimamente interessadas, os stakeholders - indivíduos ou grupos que podem afetar serem afetados pelos resultados alcançados por uma organização e portadores de reivindicações em relação ao desempenho organizacional.

Este trabalho tem como objetivo examinar as práticas de responsabilidade social desenvolvidas pela Natura S.A., empresa de capital aberto, com atuação na área de cosméticos e saúde, e apontada pelo Instituto Ethos de Empresas e Responsabilidade Social, por seis anos consecutivos, como destaque por sua atuação social. Para alcançar o objetivo proposto, foi realizada uma pesquisa bibliográfica sobre o embasamento teórico dos conceitos de stakeholder e responsabilidade social, e elaborado um estudo de caso da empresa, tendo, como objeto, as práticas corporativas voltadas para o atendimento de demandas sociais por ética e responsabilidade social dos seus principais stakeholders. Como fonte de dados foram 
Comunicação, marketing e responsabilidade social: o caso Natura

de José Américo Tristão, Virgínia Talaveira Valentini Tristão, Elias Frederico e Augustin Rodrigues

utilizados os Balanços Sociais referentes ao período de 2000 a 2005 e entrevistas efetuadas com diretores e gerentes da empresa.

Os resultados da análise demonstram haver relação entre as demandas dos stakeholders e a modificação do comportamento empresarial. Também confirmam que a qualidade das relações mantidas com os stakeholders contribui para o desenvolvimento da cidadania, destacando-se a atuação e orientação da empresa para práticas de Responsabilidade Social em razão da existência de uma cultura corporativa voltada à qualidade de relacionamentos com os stakeholders, ao desenvolvimento de ações e programas endereçados ao atendimento de necessidades tanto de clientes internos, os colaboradores da empresa, quanto externos, clientes e outros públicos interessados.

\section{MARKETING SOCIAL}

As mudanças ocorridas no papel das empresas aliadas ao crescimento da participação das empresas privadas no total das riquezas mundiais têm gerado discussões sobre o papel das organizações do mercado em questões de interesse público, especialmente na década de 90. Nesse contexto, novas práticas gerenciais e estratégicas são adotadas e novas posturas valorizadas pela sociedade, como aquelas voltadas à preservação do meio ambiente e ao desenvolvimento comunitário. No campo do marketing, novos termos multiplicaram-se, muitas vezes utilizados de forma ambígua ou para designar práticas distintas, o que ocorre com o próprio conceito de marketing. Percebe-se a existência de uma série de significados para a palavra marketing, gerando uma diluição conceitual e o emprego inadvertido de um mesmo conceito para designar práticas diferentes. Segundo a mais nova definição da American Marketing Association (AMA, 2004), marketing é "uma função organizacional e uma série de processos para a criação, comunicação e entrega de valor para clientes, e para o gerenciamento de relacionamentos com eles, de forma que beneficie a organização e seus stakeholders." (DARROCH et al 2004). Em uma concepção tradicional, marketing refere-se a um processo social e gerencial pelo qual indivíduos e grupos obtêm o que necessitam e desejam por meio da criação, oferta e troca de produtos de valor com os outros (SCHIAVO, 1999). Essa definição envolve elementos que não se restringem a processos gerenciais, mas englobam processos de relacionamentos sociais. Conflitos potenciais podem surgir com base na contraposição entre desejos e interesses dos consumidores e o bem-estar da sociedade em longo prazo. 
Comunicação, marketing e responsabilidade social: o caso Natura

de José Américo Tristão, Virgínia Talaveira Valentini Tristão, Elias Frederico e Augustin Rodrigues

KOTLER (1998) destaca que as empresas devem avaliar constantemente se estão praticando marketing na forma ética e socialmente responsável. Sugere uma reflexão sobre técnicas de vendas que invadem a privacidade das pessoas. Técnicas de pressão para forçar as pessoas a comprarem e de aceleração da obsolescência de bens. De acordo com esse ponto de vista, há a proposição de ampliar a concepção tradicional do marketing, definindo-o como marketing societal em que a tarefa da organização é a de determinar necessidades, desejos e interesses de participação de mercado e proporcionar a satisfação desejada mais efetiva e eficientemente do que a concorrência, de forma a preservar ou aumentar o bem-estar do consumidor. Assim, o marketing deve preocupar-se com algumas questões fundamentais da atualidade, sejam elas de cunho ambiental, no que se refere à escassez de recursos e à deterioração do meio ambiente, sejam elas de cunho humano, no que se refere à explosão populacional, à fome e à pobreza mundial.

Segundo esse novo conceito de marketing, as empresas devem levar em consideração três dimensões para definirem suas estratégias: os lucros, a satisfação dos desejos dos consumidores e o interesse público. Atualmente, o marketing passou da preocupação com a maximização dos lucros em curto prazo ao reconhecimento da importância da satisfação dos desejos dos consumidores. De uma disciplina de gestão empenhada em aumentar as vendas, passa a ser aplicado como uma ciência comportamental concebida com base no equilíbrio entre sistemas de compra e venda, ou seja, um sistema de troca. Agora, a disciplina torna-se atenta para os interesses da sociedade em suas tomadas de decisões. Destaca-se que a utilização das ferramentas de marketing não se restringe a um tipo específico de organização. Podem ser empregadas em todos os modelos de organizações - do governo, do terceiro setor e do mercado - adaptando-se aos objetivos e às características de cada uma.

Segundo SCHIAVO (1999) expressão marketing social foi utilizada pela primeira vez em 1971, por KOTLER e ZALTMAN, descrevendo como um processo de criação, implementação e controle de programas para influenciar aceitabilidade de idéias sociais. Mais tarde, o próprio KOTLER conceituou marketing social como o emprego de princípios e técnicas de marketing para a promoção de uma causa, idéia e/ou comportamento. No trabalho de pesquisa, identificam-se conceitos diferenciados de marketing, e o principal argumento é de que marketing social é a gestão estratégica do processo de mudança social com base na adoção de novos comportamentos, atitudes e práticas, nos âmbitos individual e coletivo, orientada por preceito ético, fundamentada nos direitos humanos e na igualdade social. Essa 
Comunicação, marketing e responsabilidade social: o caso Natura

de José Américo Tristão, Virgínia Talaveira Valentini Tristão, Elias Frederico e Augustin Rodrigues

concepção enfatiza a questão de mudança de comportamento como uma estratégia de transformação social.

SCHIAVO (1999) indica a utilidade do marketing para a promoção de mudanças de comportamento, mas atentando para as especificidades de cada contexto. Assim, quando o governo realiza uma campanha para prevenção da Aids, procura promover uma mudança de comportamento na população por meio do incentivo ao uso de preservativos. Para isso utiliza promoção, distribuição e outros elementos de um composto de Marketing.

\section{RESPONSABILIDADE SOCIAL EMPRESARIAL}

O conceito de responsabilidade social empresarial está relacionado a diferentes abordagens. Segundo CARROL (1991), pode referir-se, à contribuição social voluntária ou à associação a uma causa específica, implicando, acima de tudo, um modelo de gestão que ultrapassa a lei e a simples filantropia. Conforme OLIVEIRA NETO (2000), para que uma conduta seja considerada como socialmente responsável, haverá necessidade de reavaliar todos os seus processos e valores, além da postura ética e da forma como ela se relaciona com seus diversos públicos: funcionários, fornecedores, clientes, consumidores, acionistas, comunidade, poder público, bem como com o próprio meio ambiente. DUARTE apud CORRÊA (1997) afirma que o conceito de Responsabilidade Social pressupõe que a organização tenha não só obrigações legais e econômicas, mas também certas responsabilidades para com a sociedade, as quais extrapolam os limites daquelas obrigações. Uma empresa não pode considerar-se socialmente responsável somente por cumprir benefícios legais, transporte, alimentos, assistência aos filhos de colaboradores enquanto trabalham.

Para SCHOMMER E FISHER (1999) toda a organização cidadã deve incorporar, em seus valores e em suas atividades, a ética empresarial como norteadora e pré-requisito fundamental, a qual diz respeito a um conjunto de princípios, ações e atitudes voltadas para a valorização da qualidade, para o respeito ao consumidor e ao meio ambiente, abarcando, também, o respeito para com todos os agentes que se relacionam com a empresa, os stakeholders.

CARROL (1991) propôs um modelo conceitual para gestores das empresas, que contempla o significado amplo da Responsabilidade Social, incluindo quatro dimensões: responsabilidade econômica, legal, ética e filantrópica, surgidas das expectativas da sociedade 
Comunicação, marketing e responsabilidade social: o caso Natura

de José Américo Tristão, Virgínia Talaveira Valentini Tristão, Elias Frederico e Augustin Rodrigues

e cuja hierarquização é representada por meio de uma pirâmide A base da pirâmide representa os níveis econômico e legal. Antes de tudo, a empresa precisa apresentar rentabilidade para atender aos acionistas, fornecedores e funcionários e governo para, posteriormente, dispor de recursos para a realização de atividades de caráter ético e filantrópico. Evidentemente que os estágios da pirâmide não implicam uma seqüência, pois é importante alcançar resultados econômicos, cumprir a lei e ter comportamento ético concomitantemente, mas sugerem uma evolução.

BENEDICTO (1997) sugere que a preocupação com o social, ao abordar essas quatro dimensões, passou a ser uma forma de marketing. De fato, a AMA (American Marketing Association, 2004) define marketing como "uma função organizacional e uma série de processos para a criação, comunicação e entrega de valor para clientes, e para o gerenciamento de relacionamentos com eles, de forma que beneficie a organização e seus stakeholders." (DARROCH et al 2004). Deste modo, Responsabilidade Social pode ser definida como o dever da empresa de ajudar a sociedade a atingir seus objetivos, levando em consideração a satisfação de suas necessidades. É uma maneira de a empresa mostrar que sua existência não se vincula apenas à exploração de recursos econômicos e humanos, mas também à contribuição com o desenvolvimento social. necessidades

FERREL (2000), observa que ética refere-se aos padrões que definem a conduta aceitável determinada pelo público, órgãos regulamentadores, grupos privados interessados, concorrentes e a própria organização. $\mathrm{O}$ mais básico desses princípios foi codificado como leis e regulamentos para induzir as empresas a atenderem às expectativas de conduta da sociedade. Entretanto, é importante entender que a ética de marketing vai além das questões legais: as decisões éticas de marketing favorecem a confiança, que ajuda a construir relacionamentos de longo prazo (MORGAN e HUNT, 1994). Há ampla evidência de que desconsiderar essas questões pode destruir a confiança dos consumidores e resultar na intervenção governamental ou na própria extinção da empresa. Para FERRELL (2001) a boa cidadania praticada por meio de iniciativas éticas e legais ajuda a melhorar, em longo prazo, a rentabilidade da empresa. O último degrau na pirâmide da Responsabilidade Social é o aspecto filantrópico. Cumprindo suas responsabilidades nesse particular, as empresas contribuem com recursos financeiros e humanos para melhorar a qualidade de vida da comunidade e da sociedade em geral. Ao se investigar Responsabilidade Social, freqüentemente são encontradas referências aos grupos interessados no desempenho funcional, estratégico e econômico da empresa, os stakeholders. 


\section{STAKEHOLDERS}

O papel das empresas na sociedade transcende a oferta de produtos e serviços. Questões ligadas ao trabalho, segurança, benefícios, legislação, encargos sociais, proteção a grupos especiais - deficientes físicos, gestantes - deixam de ser decididas apenas pela empresa e passam do domínio interno para o externo, sendo discutidas pela sociedade. CARROLL (1991), argumenta que é função da empresa avaliar os efeitos do seu processo de decisão no sistema social externo, de maneira a agregar benefícios sociais, além dos ganhos econômicos que a empresa procura.

Segundo JONES e WICKS (1999), stakeholders são os indivíduos e grupos capazes de afetar e de serem afetados pelos resultados estratégicos alcançados pela empresa e portadoras de reivindicações sobre o desempenho desta Assim, as organizações possuem relacionamentos de dependência com os stakeholders. Contudo, esses indivíduos ou grupos possuem níveis de influência diferenciados sobre os compromissos, decisões e ações da empresa. As partes envolvidas nas operações de uma empresa podem ser divididas em três grupos: os depositários do mercado de capitais (acionistas e as principais fontes de capital de uma empresa), os depositários dos interesses da empresa no mercado do produto (clientes primários, fornecedores, comunidades anfitriãs e sindicatos que representam a força de trabalho) e os depositários dos interesses organizacionais de uma empresa (todos os empregados da empresa, inclusive pessoal gerencial e não-gerencial). Os objetivos desses grupos geralmente são diferentes entre si. Os acionistas investiram capital com a expectativa de maximizar o retorno sobre seus investimentos. No curto prazo, essa maximização pode ser alcançada por meio da redução do investimento no futuro de uma empresa. Entretanto, um aumento em curto prazo na riqueza dos acionistas pode afetar negativamente a capacidade competitiva futura da empresa e não é do interesse do stakeholder organizacional nem do stakeholder do mercado de produto que os investimentos em uma empresa sejam reduzidos indevidamente. $\mathrm{O}$ cliente prefere que os investidores recebam um mínimo de retorno sobre seus investimentos. Assim, o cliente poderá ter seus interesses maximizados se a qualidade e a confiabilidade dos produtos de uma empresa forem melhoradas, contudo sem um aumento nos preços. Retornos elevados para o cliente podem ser gerados à custa de retornos mais reduzidos e negociados com os acionistas no mercado de capitais. Devido ao potencial de conflitos, cada empresa é desafiada a administrar os stakeholders. Primeiramente, todos os 
Comunicação, marketing e responsabilidade social: o caso Natura

de José Américo Tristão, Virgínia Talaveira Valentini Tristão, Elias Frederico e Augustin Rodrigues

stakeholders importantes deverão ser cuidadosamente identificados, deverão ser priorizados, caso a empresa não seja capaz de satisfazer todos eles.

\section{METODOLOGIA DA PESQUISA}

Para atingir os objetivos do trabalho, realizou-se uma pesquisa exploratória e descritiva com técnicas e instrumentos de coleta de dados determinados pelas necessidades de cada fase do estudo de caso. Segundo YIN (2005), o estudo de caso é utilizado como estratégia de pesquisa em muitas situações, visando a contribuir com o conhecimento que se tem dos fenômenos individuais, organizacionais, sociais, políticos e de grupo, além de outros fenômenos a eles relacionados Iniciou-se com pesquisa documental, por meio da avaliação dos Balanços Sociais da Empresa e do Guia Exame de Boa Cidadania Corporativa e, a seguir, foi realizada uma entrevista com a Gerência de Relações Corporativa. Conhecendo o modus operandi da Natura, foi possível elaborar uma pesquisa semi-estruturada. Nela, abordaram-se pontos relativos a suas atividades empresariais e socioambientais, e as relações com os diversos stakeholders. O objetivo foi conhecer a atuação e orientação da empresa para práticas de Responsabilidade Social e a existência de uma cultura corporativa voltada à qualidade de relacionamentos com os stakeholders, ao desenvolvimento de ações e programas endereçados ao atendimento de necessidades tanto de clientes internos, os colaboradores da empresa, quanto externos, clientes e outros públicos interessados. A análise dos dados se deu em função do tipo de informação coletada, com ênfase qualitativa. As informações obtidas na pesquisa foram tabuladas e analisadas.

\section{O CASO NATURA}

A Natura S.A. é uma sociedade anônima, atualmente de capital aberto, negociando suas ações no novo Mercado da Bovespa, Bolsa de Valores do Estado de São Paulo, desde maio de 2004. A empresa atua na área de cosméticos e saúde, fabrica produtos de higiene pessoal e perfumes, preparados constituídos por substâncias naturais e sintéticas ou suas misturas, de uso externo nas diversas partes do corpo humano. Na área de saúde e nutrição, produz suplementos nutricionais, vitamínicos minerais. A linha de produtos contempla uma grande variedade de itens dirigida ao mercado de perfumes, tratamento de pele, cabelos, 
Comunicação, marketing e responsabilidade social: o caso Natura

de José Américo Tristão, Virgínia Talaveira Valentini Tristão, Elias Frederico e Augustin Rodrigues

banho, barba, maquiagem e voltadas ao segmento feminino, masculino e infantil. São colocados no mercado 900 mil itens diariamente (EXAME, 2005).

A empresa atua, exclusivamente, pelo sistema de venda direta, trabalha com 483 mil consultoras que, na verdade, exercem função de revendedoras, e seus produtos são distribuídos em todas as regiões, em mais de 4.500 municípios do Brasil. Atua, também, no exterior, na Argentina, Chile, Bolívia e Peru. O objetivo é ser líder na América Latina. Em sua estratégia de inserção internacional, a empresa testou, no ano de 2005, um novo modelo de operação na Europa, com a inauguração de um espaço próprio em Paris. Localizada em Saint Germain des Prés, ponto privilegiado da capital francesa, a Casa Natura Brasil é um espaço em que o consumidor encontra produtos elaborados com ativos da biodiversidade brasileira.

Do ponto de vista operacional, as vendas em 2005 registraram crescimento de 27,3\%, acumulando $117 \%$ nos últimos três anos. O lucro líquido, de 396,9 milhões de reais, representou 17,39\% da receita líquida. As operações na América Latina também evoluíram de forma consistente, com crescimento, em dólares, de 52\% no ano e de $107 \%$ nos últimos três anos. Uma das razões para essa vitalidade foi o aumento de $15,6 \%$ no número de consultoras e consultores independentes, atingindo-se o total de 483 mil pessoas no Brasil e 36 mil no exterior. Em 2005, 63\% do faturamento foi proveniente de produtos lançados ou relançados nos últimos dois anos. O relatório anual de 2005 da Natura demonstra que 2,7\% da receita líquida foram direcionados para pesquisa e desenvolvimento e, para os próximos anos, o objetivo é realizar investimentos superiores a 3\%. Outro objetivo é a manutenção da estratégia de inovação em suas diversas dimensões: no uso sustentável de ativos da biodiversidade brasileira, em avanços tecnológicos, na comunicação de conceitos e no aprimoramento de relações com os stakeholders. Em pesquisa realizada em 2005 pelo Guia Exame, a Natura foi considerada uma empresa modelo no tocante a Responsabilidade Social. Os resultados decompostos por itens, segundo as categorias de cidadania corporativa avaliadas, são apresentados na tabela 1 .

Tabela 1 - Boa cidadania - A composição da nota obtida pela Natura 
Comunicação, marketing e responsabilidade social: o caso Natura

de José Américo Tristão, Virgínia Talaveira Valentini Tristão, Elias Frederico e Augustin Rodrigues

la cidadania - A composição da nota obtida pela Natura em

\begin{tabular}{lc}
\hline \multicolumn{1}{c}{ ITEM } & DESEMPENHO DA EMPRESA \\
\hline Valores e transparência & 8,5 \\
Funcionários & 8 \\
Meio Ambiente & 9,5 \\
Fornecedores & 8 \\
Consumidores/clientes & 9 \\
Comunidade & 8 \\
Governo e sociedade & 6 \\
Nota média & 8,1 \\
\hline Adaptado de Guia Exame, A Boa Cidadania, dez.2005.
\end{tabular}

A análise das notas demonstra que o maior resultado da empresa está no item meio ambiente, seguido do item consumidores/clientes. Em terceiro lugar, está o item valores e transparência. Esses resultados demonstram que a empresa tem, entre suas práticas, foco em valores, ética, preservação e cliente. Esse foco é amplamente divulgado em suas ações de comunicação e marketing, tanto no aspecto comercial como no institucional, levando a Natura a ser uma das marcas mais conhecidas de cosméticos no Brasil e freqüentemente associadas a ações de Responsabilidade Social e preservação do meio ambiente.

\section{MAPEAMENTO E GESTÃO DE STAKEHOLDERS}

De acordo com os executivos entrevistados, a empresa manifestou uma preocupação com o retorno dos públicos em relação aos esforços desenvolvidos por ela com o objetivo de aprimorar resultados e aperfeiçoar vínculos. A empresa desenvolve pesquisa para mensurar os níveis de favorabilidade, ou aceitação, de suas ações e políticas. Desde o final da década de 1990, a Natura alega priorizar a Responsabilidade Social, colocando-a no centro de sua estratégia e de sua gestão, com base em dois pilares: o relacionamento ético e transparente com os diversos públicos, os stakeholders, e a definição de metas compatíveis com o desenvolvimento sustentável. Nos últimos anos, a companhia tem buscado estabelecer processos e sistemas que garantam a incorporação desses princípios ao planejamento estratégico e ao dia-a-dia do negócio. Em 2004, o balanced scorecard da companhia passou a refletir as três dimensões da sustentabilidade, desenhando um mapa estratégico que contempla metas econômico-financeiras e socioambientais. No planejamento estratégico, esse modelo se desdobra por toda a companhia, influenciando as ações das diversas diretorias. O que dá suporte a esse processo, do ponto de vista das metas e dos indicadores sociais, é o Sistema de Gestão de Responsabilidade Corporativa, criado há cerca de dois anos e aperfeiçoado em 
Comunicação, marketing e responsabilidade social: o caso Natura

de José Américo Tristão, Virgínia Talaveira Valentini Tristão, Elias Frederico e Augustin Rodrigues

2004 e 2005. Por meio desse sistema, foi feito o diagnóstico detalhado do relacionamento da Natura com seus diversos públicos - o que resultou no levantamento de temas a serem incorporados ao planejamento estratégico. Com isso, todas as áreas da Natura passam a acompanhar, sistematicamente, as questões relativas à qualidade da relação com os diversos públicos, com base em aspectos como ética, transparência e eficiência dos canais de diálogo, inclusive para temas não-negociais. As ações relacionadas aos aspectos críticos da gestão socialmente responsável são acompanhadas por meio da Matriz de Investimentos em Responsabilidade Corporativa.

\subsection{Colaboradores e consultores}

Até fins do ano de 2005, a Natura empregava 3.177 colaboradores no Brasil e 378 no exterior - Argentina, Chile, Peru. Em 2005, esse número passou a 4.128 colaboradores, sendo $63 \%$ mulheres, justificado pela empresa por ser um negócio relacionado a cosméticos e beleza. Apesar de ser maioria, o salário médio auferido pelas mulheres é menor que o dos homens (Tabela 3). De acordo com informações da empresa na área de produção, que contém sete níveis salariais, essa diferença é conseqüência do fato de que 98,5\% das mulheres estão nos níveis salariais 1, 2 e 3 (mais baixos), enquanto a proporção de homens nesses patamares é de 79,8\%. Os cargos de eletricista, manipulador, mecânico, preparador de máquina e torneiro mecânico, em que os salários são mais elevados, são ocupados, predominantemente, por homens, seguindo padrão social dessas funções. No grupo gerencial, que contém seis níveis salariais, a diferença de média entre homens e mulheres é conseqüência do fato de que 71,2\% das mulheres estão nos três níveis gerenciais mais baixos do que as faixas em que estão $51 \%$ dos homens.

Tabela 2

Perfil de salários por segmento em R $\$$

\begin{tabular}{lrr}
\hline \multicolumn{1}{c}{ SETOR DE TRABALHO } & HOMENS & MULHERES \\
\hline Salários médios mensais em cargos de produção & $1.084,00$ & 824 \\
Salários médios mensais em cargos administrativos & $4.068,00$ & $4.330,00$ \\
Salários médios mensais em cargos gerenciais & $11.059,00$ & $9.901,00$ \\
Salários médios mensais em cargos de diretoria & $33.084,07$ & $23.272,00$ \\
\hline
\end{tabular}

Fonte: Adaptado do Relatório Anual, 2005, Natura. Publicado em abril de 2006

Apesar da questão salarial, a empresa é reconhecida como referência em ambiente de trabalho no Brasil e, em 2004, foi escolhida como A Melhor Empresa para a Mulher 
Comunicação, marketing e responsabilidade social: o caso Natura

de José Américo Tristão, Virgínia Talaveira Valentini Tristão, Elias Frederico e Augustin Rodrigues

Trabalhar, de acordo com levantamento publicado no Guia Exame - Você S.A. As Melhores Empresas para Você Trabalhar, em parceria com o Great Place to Work Institute. Ressalta-se, também, a ampliação dos investimentos e das ações do Natura Educação, programa de reembolso de mensalidades de cursos de formação básica e especialização, para colaboradores e seus filhos.

Além de programas para o incentivo da poupança (Poupança Incentivada Natura), os colaboradores têm direito a participação nos resultados alcançados pela companhia. O Programa de Participação nos Lucros continuou a se mostrar um diferencial na remuneração dos colaboradores. Em bases comparáveis, os valores provisionados para o pagamento da PLR em 2005 cresceram 46,9\% em relação a 2003.

A empresa investe na capacitação dos seus colaboradores de forma crescente, passando de $\mathrm{R} \$ 12,6$ milhões em 2005. Esses investimentos contemplam os executivos, bem como o treinamento das promotoras e consultoras, profissionais relacionados à força de vendas que não estão ligados à Natura por contrato de trabalho e pela Consolidação das Leis do Trabalho, CLT, mas possuem vínculo empregatício. De acordo com os entrevistados, a manutenção de um clima organizacional diferenciado é um desafio permanente na Natura. Mesmo assim, os índices de satisfação são declinantes (Tabela 3).

Tabela 3 - Satisfação de Colaboradores

\begin{tabular}{lccrr}
\hline & 2003 & 2004 & 2005 \\
\hline Favorabilidade (\%) & 76 & 73 & 70 \\
\hline Fonte: Adaptado de Relatório Anual & 2005 & Natura.
\end{tabular}

O resultado da pesquisa de satisfação realizada com colaboradores, pela empresa Natura, demonstra que houve decréscimo nos níveis de satisfação dos colaboradores: $-3,9 \%$ de satisfação em 2004 em relação a 2003 e 4,1\% de 2005 em relação a 2004. A empresa informa que incluiu, na pesquisa de satisfação, os colaboradores indiretos e terceirizados, visto que fazem parte do cotidiano da empresa, mas, pelo fato de muitas vezes não agirem de acordo com as crenças e valores, podem ter influenciado o resultado. A empresa informou que, a partir de 2006, programará novas políticas de relacionamento e avaliação das relações com seus colaboradores a fim de obter melhores resultados.

As consultoras - profissionais independentes que compram e revendem os produtos da Natura - representam a principal ligação da companhia com o consumidor final. A empresa manifesta ter, como objetivo, estabelecer com elas uma relação de parceria e reconhece o 
Comunicação, marketing e responsabilidade social: o caso Natura

de José Américo Tristão, Virgínia Talaveira Valentini Tristão, Elias Frederico e Augustin Rodrigues

papel que exercem na disseminação dos conceitos e dos valores da companhia. Em 2005, a Natura ampliou o conjunto de programas que visam reconhecer o valor do relacionamento com as consultoras, reforçando atributos expressos em vários níveis - tempo na atividade, número de clientes, volume de compras, presença em eventos e frequiência nos encontros promovidos pela empresa, em que são apresentados os lançamentos.

O relacionamento cada vez mais próximo e a força da marca Natura têm estimulado a atração de consultoras. Como já apresentado, a empresa encerrou 2005 com 483 mil consultoras no Brasil, o que representa um crescimento de 14,6\% em relação a 2003. Nos outros países em que a companhia está presente, o número aumentou 30\%, alcançando 36 mil. A produtividade das consultoras (vendas por consultoras ativas) aumentou 10,2\% no Brasil, em reais, e 10,7\% nas operações internacionais, em dólares. Para esse grupo importante da Comunidade Natura, a companhia gerou uma renda estimada de $\mathrm{R} \$ 1,06$ bilhão.

Em 2005, a Natura registrou 472 mil participações em treinamento com essas consultoras, em comparação com 319 mil em 2003. O elo da Natura com as consultoras são as promotoras de vendas, que se reportam às gerências de vendas. Com a ampliação das equipes, a relação de promotoras atendidas por gerência caiu de 35 para 20. Coerente com seus programas de relacionamento e atração em 2005 , a Natura preencheu com consultoras $70 \%$ das vagas de promotoras de vendas resultantes da ampliação das equipes.

O relacionamento da Natura com os consultores é cultivado de variadas formas: por meio de reuniões periódicas, pelo site e por uma linha telefônica gratuita. A forma mais direta, entre as mencionadas, são as reuniões com as promotoras de vendas. Nesses encontros, além de receber informações sobre produtos e a forma de administrar as atividades de venda, assistem a vídeos, recebem materiais de apoio e participam de discussões sobre valores e práticas da empresa. $\mathrm{Na}$ internet, consultoras e consultores contam com espaço para tirarem dúvidas, pelo atendimento on-line, para enviarem pedidos, mandarem e receberem e-mails para divulgar promoções, ofertas, e últimos lançamentos. De acordo com a Gerência de Relações Corporativas, o Centro de Atendimento Natura, CAN, atua no gerenciamento da satisfação de consultoras e consultores, efetuando pesquisas de satisfação e tratando de todas as manifestações e acompanha os processos até sua resolução. A análise dos números e das informações complementares demonstra que o nível de favorabilidade obtidos na categoria de consultores teve seu ápice em 2003, com 92\% de satisfação. Em janeiro de 2005 esse índice foi de $89 \%$. 
Comunicação, marketing e responsabilidade social: o caso Natura

de José Américo Tristão, Virgínia Talaveira Valentini Tristão, Elias Frederico e Augustin Rodrigues

\subsection{Consumidores}

O respeito ao consumidor é, segundo a Gerência de Relações Corporativas, um dos princípios mais importantes da Natura. A empresa investe na formação de consultoras para que a relação com o consumidor seja ética e transparente e para que ele se sinta bem atendido e conheça as crenças e os valores da empresa. Os textos de rotulagem dos cosméticos Natura estão de acordo com as resoluções 211, de 14 de julho de 2005; 79, de 28 de agosto de 2000; e 335, de 22 de julho de 1999 da Agência Nacional de Vigilância Sanitária, Anvisa, e respeitam as diretrizes do Código de Proteção e Defesa do Consumidor. Também são observadas as normas do Instituto Nacional de Metrologia, Normalização e Qualidade Industrial - Inmetro. A empresa utiliza seus rótulos e prospectos como veículos de conhecimento. Neles, os consumidores encontram, além de informações detalhadas sobre os produtos e seus benefícios, reflexões sobre temas relacionados aos conceitos que os originaram.

A Natura possui um Comitê de Segurança de Produtos, cuja missão é manter atualizada a Política sobre Segurança de Produtos Natura e emitir pareceres mandatários sobre o desenvolvimento de todos os produtos no que diz respeito à segurança de uso por humanos. Somente após recebimento desse parecer, a área responsável pelo registro na Anvisa requer as autorizações necessárias. A Política sobre Segurança de Produtos Natura estabelece os critérios de avaliação pré-clínica e clínica de todos os produtos em desenvolvimento antes de serem lançados no mercado. A principal estratégia de segurança é a avaliação toxicológica de todas as matérias-primas constantes nas fórmulas, de acordo com padrões internacionais. Para isso, a empresa mantém um laboratório de bioquímica e pele reconstituída, com equipamentos de última geração para testes in vitro em cultura de células. Esses testes seguem as indicações de agências internacionais, como a Food and Drug Administration, dos Estados Unidos, e a Sétima Diretiva da União Européia.

A Natura também possui, também, um Centro do Consumidor, no qual são realizados testes de eficácia dos diversos produtos existentes e avaliações de desempenho dos novos. Além disso, a empresa mantém amostras de cada lote de produtos encaminhados ao mercado, pelo tempo de validade de cada um. Colocam em prática, também, os conceitos de cosmetovigilância, ou seja, a avaliação sistemática de reações adversas dos produtos que comercializa. Os consumidores que têm algum tipo de reação a um produto dentro do prazo de validade são atendidos por uma equipe especializada ou por dermatologistas para que seja 
Comunicação, marketing e responsabilidade social: o caso Natura

de José Américo Tristão, Virgínia Talaveira Valentini Tristão, Elias Frederico e Augustin Rodrigues

estabelecida uma relação causal clara. Com o uso dessas informações, as áreas pertinentes da empresa são orientadas para aprimorar o produto em questão ou para alimentar um sistema de informações que auxilie na melhoria da comunicação comercial e, posteriormente, na confecção de outros artigos. Para relacionar-se diretamente com seus clientes, a empresa instituiu o Serviço Natura de Atendimento ao Consumidor, Snac, que atua no gerenciamento da satisfação dos clientes. Em 2005, havia contra a Natura, 17 processos administrativos no Procon. Este número é considerado como muito baixo pela empresa.

\subsection{Fornecedores}

De acordo com a Gerência de Relações Corporativas, a Natura trabalha com o objetivo de estreitar os vínculos com esses fornecedores e parceiros e, para isso, introduziu o conceito Qlicar, sigla que resume os aspectos qualidade, logística, inovação, contrato, atendimento e rastreabilidade. $\mathrm{Na}$ área de transportes, a empresa decidiu centrar o relacionamento em operadores logísticos, capazes de cuidar de toda a distribuição, da coleta do produto desde a fábrica até a entrega para a consultora. Com infra-estrutura adequada, as transportadoras executam, com mais eficiência, um processo de distribuição complexo - os produtos da Natura chegam a mais de 5 mil municípios brasileiros. Segundo a empresa, o próximo passo será dar a esses fornecedores a tarefa de recolher, na casa do consumidor, produtos objeto de reclamação.Um projeto piloto em São Paulo indicou que 95\% dos consumidores mostraramse satisfeitos com o serviço. A Natura procura fornecedores que possam compartilhar com a empresa crenças e valores. No contexto da preocupação com o meio ambiente, cada fornecedor recebe um questionário sobre temas ambientais nas suas operações, de acordo com padrões da NBR ISO 14001. Quando há itens não cumpridos, porém toleráveis, estabelece-se um plano de ação para suprimir as falhas. Fornecedores, nessa situação, são qualificados para o relacionamento comercial com a Natura e, superados os problemas, podem ser certificados. Fornecedores certificados são aqueles cujos produtos e serviços são pré-aprovados e cujo recebimento independe de conferência. As primeiras certificações, já dentro do conceito Qlicar, foram efetuadas em 2005. Segundo levantamento interno efetuado na empresa, e disponibilizado pelos entrevistados, os fornecedores apresentavam, em junho de 2005, um índice de satisfação de $83 \%$ com a Natura. Os entrevistados denotaram sinais de preocupação com esse índice, já que ele era de 93\% em janeiro de 2004. 
Comunicação, marketing e responsabilidade social: o caso Natura

de José Américo Tristão, Virgínia Talaveira Valentini Tristão, Elias Frederico e Augustin Rodrigues

Ao lançar a linha Ekos, em 2000, a Natura declarou ter, como objetivo, a prática do uso sustentável de ativos da biodiversidade brasileira. O emprego de originários da flora do Brasil deveria ser economicamente viável e, ao mesmo tempo, contemplar o manejo correto da atividade extrativista e o desenvolvimento sustentável das comunidades produtoras. Desde então, o relacionamento com as comunidades fornecedoras de ativos da biodiversidade tem se traduzido em importante aprendizado. Os progressos observados em 2004 refletem a aplicação desse aprendizado no processo de construção de um modelo coerente de uso dos ativos e de relacionamento. Durante 2004, uma equipe multifuncional trabalhou na montagem de um modelo que pudesse, com base em uma experiência piloto com a comunidade de Iratapuru, no estado do Amapá, ser utilizado em outras comunidades. A comunidade de Iratapuru é constituída de 30 famílias fornecedoras de castanha, copaíba e breu-branco. A experiência foi acompanhada pela ONG Amigos da Terra, que, junto à comunidade, criou um plano de gestão de negócios. Uma conquista relevante foi a certificação dos três ativos produzidos pela comunidade, pelo Forest Stewardship Council, FSC.

Entre as medidas tomadas, está a criação de uma reserva constituída por um percentual da receita líquida obtida com a venda dos produtos originados dos ativos fornecidos pela comunidade. Esses recursos podem ser usados para atender a necessidades imediatas ou futuras. Além disso, uma consultoria especializada em desenvolvimento sustentável da região, a Amapaz, fará um diagnóstico da comunidade com intuito de elaborar um plano para o futuro, que pode incluir outras atividades, além da extrativista. O diagnóstico incluirá os aspectos físicos, territoriais e socioeconômicos, de modo a ajudar a comunidade a elaborar um plano de desenvolvimento sustentável.

\subsection{Comunidades de entorno}

Com unidades em Cajamar e Itapecerica da Serra, ambas no estado de São Paulo, a Natura buscou estreitar seu relacionamento com as comunidades desses municípios. Em Cajamar, as duas frentes criadas, em 2003, para melhorar o relacionamento da empresa com a cidade, atuaram, ativamente, por meio do trabalho de um grupo interno formado por colaboradores de diversas áreas para debater e propor soluções para as carências do município. A empresa apoiou a elaboração do plano diretor para a educação e estabeleceu parcerias com as escolas, para a realização de eventos, como a Semana do Meio Ambiente. 
Comunicação, marketing e responsabilidade social: o caso Natura

de José Américo Tristão, Virgínia Talaveira Valentini Tristão, Elias Frederico e Augustin Rodrigues

O grupo tripartite, formado por representantes da Natura, da ONG Mata Nativa e da prefeitura local, assinou um termo de cooperação para a implantação, na cidade, da Agenda 21, plano de ação para o desenvolvimento sustentável estabelecido na I Conferência das Nações Unidas sobre Meio Ambiente e Desenvolvimento, a Eco-92. Além disso, com a colaboração de lideranças locais, elaborou um diagnóstico pormenorizado de Cajamar, com diversos indicadores socioeconômicos e ambientais, conduzido pela ONG Oficina Municipal.

Também foi instalado o Fórum Pró-Agenda 21 de Cajamar, constituído de organizações governamentais, não-governamentais, empresas e cidadãos do município. $\mathrm{O}$ fórum é responsável por acompanhar e pautar as políticas públicas da cidade.

Em Itapecerica da Serra, a Natura decidiu centrar atenções e esforços no bairro de Potuverá, onde está instalada uma de suas unidades. Colaboradores da empresa organizaramse, voluntariamente, em 2004, para criar um grupo de trabalho e programar projetos de formação educacional, de capacitação tecnológica e outros de interesse da comunidade. Em 2005, a Natura iniciou processo para a implantação da Agenda 21 no município.

Tanto em Cajamar quanto em Itapecerica da Serra, a empresa mantém um programa de voluntariado no horário de trabalho. Em 2004, participaram do programa mais de 100 colaboradores. Uma linha 0800 , de ligação gratuita, foi colocada à disposição da comunidade de Cajamar para comunicação com a Natura. O mesmo foi feito em 2005 para a comunidade de Itapecerica da Serra.

O GT Tripartite, composto por Natura, prefeitura de Cajamar e ONG Mata Nativa, concentrou boa parte dos seus esforços na estruturação e preparação do Fórum Permanente da Agenda 21 de Cajamar. O fórum instalou-se, oficialmente, em dezembro de 2005, depois de uma seqüência de atividades educativas, de formação e discussão em escolas e bairros da cidade. Em seminários preparatórios, foram discutidos o significado de planejamento participativo, Agenda 21, e a importância do envolvimento da comunidade nesse processo. A finalidade foi criar oportunidades de crescimento para o município, respeitando o meio ambiente e melhorando as condições de vida dos moradores. Utilizou-se, como ponto de partida desses trabalhos, o diagnóstico participativo feito em 2005, conforme observado no quadro 5 a seguir. Merece destaque o fato de que os seminários realizados envolvem profissionais da área educacional e representantes religiosos que atuam como formadores de opinião e agentes multiplicadores de iniciativas e propostas da empresa que visam o desenvolvimento da comunidade. Em um segundo momento, foram realizados fóruns distritais, nos quais se definiram as prioridades de trabalho, em 2006, para cada distrito de 
Comunicação, marketing e responsabilidade social: o caso Natura

de José Américo Tristão, Virgínia Talaveira Valentini Tristão, Elias Frederico e Augustin Rodrigues

Cajamar. Segundo a empresa, essas prioridades foram apresentadas no fórum municipal realizado em dezembro de 2005.

Como forma de apoio à implantação da Agenda, foram organizados cursos e espaços de discussão para dar subsídio teórico aos participantes. O primeiro curso, sobre a utilização do software Spring, teve como objetivo preparar um grupo de cidadãos, principalmente jovens, para a estruturação de um banco de dados sobre Cajamar, de forma a complementar e atualizar as informações contidas no diagnóstico do município, realizado em 2004. O curso sobre plano plurianual, PPA, e lei orçamentária anual, LOA, destinou-se a subsidiar as lideranças para participação na construção do PPA, no período 2006-2009, e prepará-las para o acompanhamento da LOA.

\subsection{Stakeholders ligados ao meio ambiente}

De modo a atender demandas de stakeholders representantes de movimentos ambientalistas, a Natura demonstra trabalhar de maneira comprometida com a construção de caminhos para a promoção do desenvolvimento sustentável e compartilha esse compromisso com os diversos públicos. Entre os principais stakeholders ambientais destacam-se as comunidades fornecedoras de ativos de biodiversidade. Nesse contexto, por exemplo, suas relações com as comunidades fornecedoras contemplam a conservação do meio ambiente e o desenvolvimento local. Além disso, a empresa procura manter o controle sobre suas atividades, produtos e serviços, de tal forma que o meio ambiente possa absorver os impactos deles resultantes. Para isso, usa como ferramenta, o Sistema de Gerenciamento Ambiental Natura, Sigan, que tem por base a NBR ISO 14001 - a companhia possui a certificação NBR ISO 14001, obtida em maio de 2004. O monitoramento feito por meio do Sigan permitiu identificar pontos falhos no consumo de água e energia e promover o uso mais eficiente desses recursos, em um ano no qual a produção cresceu $28 \%$.

Por considerar a água um recurso de grande valor a ser gerenciado com cautela, a Natura projetou as instalações da fábrica de Cajamar de modo a permitir sua reutilização. No poço mantido no local, foi instalado um sistema que só permite à empresa retirar a quantidade de água que o lençol tem capacidade de recarregar. Para tornar cada vez menor a necessidade de extrair água do poço e reduzir o consumo de maneira geral, o aumento da taxa de reutilização da água é meta permanente. Em 2005, a empresa conseguiu uma redução de $23 \%$ no consumo por unidade vendida. A reutilização da água aumentou de 29\%, em 2004, para 
Comunicação, marketing e responsabilidade social: o caso Natura

de José Américo Tristão, Virgínia Talaveira Valentini Tristão, Elias Frederico e Augustin Rodrigues

39,5\%, em 2005. A questão da água é recorrente nas discussões da Natura com os diversos públicos.

No que diz respeito à energia, a Natura procura garantir que o crescimento industrial não tenha relação direta com o crescimento do consumo absoluto. Para isso, desenvolve sistemas e processos que permitam o uso racional da energia disponível. Em 2005, a empresa apresentou ganhos de escala que provocaram a diluição de gastos fixos, o que permitiu redução de $23 \%$ no consumo por unidade vendida.

Quanto à geração de resíduos, conseguiu-se, em 2005, uma redução de 12,3\% por unidade vendida, em relação a 2003. A incineração dos resíduos diminuiu de 6,4\%, em 2003, para $5,4 \%$, em 2005, e o descarregamento em aterros, de $24,4 \%$ para $21,2 \%$. O percentual de resíduos reciclados subiu de $69,2 \%$ para $73,4 \%$.

A Natura informa identificar o impacto ambiental de seus produtos e as possíveis conseqüências para a sociedade. Para isso, utiliza a metodologia da análise de ciclo de vida. Em 2004, todas as embalagens do portfolio foram analisadas, segundo essa metodologia. Em 2005, a Natura desenvolverá e testará um modelo de análise do ciclo de vida de matériasprimas.

\subsection{Acionistas}

Como empresa de capital aberto desde maio de 2004, a Natura se propõe a estabelecer um relacionamento exemplar com a comunidade de acionistas, da mesma forma que procura fazer com seus demais públicos. A empresa declara que possui como objetivo de que esse relacionamento seja marcado pela comunicação transparente, pelo tratamento justo e igualitário e pelo aprimoramento constante da governança corporativa. A área de Relações com Investidores participa continuamente de conferências programadas por bancos de investimentos dentro e fora do Brasil e de reuniões com a Associação de Analistas e Profissionais de Investimento do mercado de Capitais, Apimec, além de realizar eventos com pessoas físicas como procuram atender de forma direta pessoas interessadas em se tornar acionistas. O site da empresa é utilizado como um importante canal de comunicação com esses stakeholders.

\subsection{Governo e sociedade}


A Natura mantém canais de diálogo com os governos federal, estadual e municipal, bem como com parlamentares. Além disso, ciente de que a empresa deve ser responsável pela transformação social, faz parte de sua política ampliar, permanentemente, as iniciativas voltadas para o desenvolvimento da sociedade.Durante o exercício de 2004, a Natura estabeleceu importantes acordos com governos e organizações da sociedade civil. Destacamse o termo de cooperação assinado com a prefeitura de Cajamar e a ONG Mata Nativa para implantação da Agenda 21 nesse município além da parceria com a Fundação Abrinq e o Ministério da Educação pela promoção da Educação de Jovens e Adultos, como parte do "Programa Crer para Ver".Como membro da Associação Brasileira das Empresas de Vendas Diretas, a Natura foi signatária do termo estabelecido pela organização com o Ministério da Previdência Social para promover a educação para a previdência de revendedoras autônomas.

A Natura representou o setor empresarial brasileiro na Conferência da International Organization of Standardization sobre Responsabilidade Social, realizada em junho de 2004, quando foi decidido criar, até 2008, diretrizes para normatizar a aplicação de processos na área. A empresa fará parte, também, do comitê responsável pela definição de guidelines da norma. Além disso, representantes da Natura foram chamados a participar de importantes fóruns cujos temas envolvem a sociedade civil, como o Fórum de Competitividade de Cosméticos, o Fórum de Competitividade de Biotecnologia e a Conferência Nacional do Meio Ambiente, além de grupos de trabalho que discutem acesso ao patrimônio genético e remuneração do conhecimento tradicional, entre outros.

Um dos instrumentos de atuação da Natura no relacionamento com a sociedade é o programa "Crer para Ver", mantido em parceria com a Fundação Abrinq. Por meio do "Crer para Ver", as consultoras Natura vendem, voluntariamente, produtos, em especial criados para o programa, destinando os recursos arrecadados a projetos da rede pública de ensino. Nos seus nove anos de existência, arrecadou $\mathrm{R} \$ 17,9$ milhões e apoiou 148 projetos em 3.638 escolas. A arrecadação em 2004 foi a maior em toda a história do programa.

Entre os projetos apoiados em 2004, estão o Cinema e Vídeo Brasileiro nas Escolas, de São Paulo, e o Projeto Chapada, na Bahia. O Cinema e Vídeo têm como objetivo incentivar a criação de videotecas em escolas e o aprendizado dos alunos por meio da linguagem audiovisual, com base na formação de professores. O Chapada tem foco na construção de uma rede de ensino público de qualidade na região da Chapada Diamantina, por meio da formação adequada de coordenadores pedagógicos e professores e do desenvolvimento de ações conjuntas com secretarias municipais de educação para combate ao trabalho infantil. 
Comunicação, marketing e responsabilidade social: o caso Natura

de José Américo Tristão, Virgínia Talaveira Valentini Tristão, Elias Frederico e Augustin Rodrigues

O "Crer para Ver" teve seu escopo ampliado em 2004, com a criação do "Crer para Ver EJA", relacionado com a Educação de Jovens e Adultos, em parceria com o Ministério da Educação e a Fundação Abrinq. No "Crer para Ver EJA", as consultoras são incentivadas a identificar pessoas acima de 15 anos que não concluíram o ensino fundamental e encaminhá-las de volta à escola. Além disso, a Natura apóia iniciativas voltadas à cultura, à promoção de canais de diálogo e do desenvolvimento sustentável e à proteção do meio ambiente.

É atribuição da gerência de Relações Governamentais, especialmente, criar oportunidades de parcerias e de relacionamento para promoção e disseminação, na sociedade, de conceitos de responsabilidade corporativa e desenvolvimento sustentável. Integrantes dessa área também acompanham ou representam os principais executivos da Natura nessas ocasiões. Em 2005, foi criado o Sistema de Gestão em Relações Governamentais, que definiu o processo da gerência, assim como atribuições, principais atividades e subprocessos relacionados a ela. Apesar de os códigos de relacionamento com o poder público, assim como as políticas sobre contribuição de campanha, lobby, corrupção e suborno, ainda não estarem formalizados, a Natura tem, como fio condutor de seu relacionamento com o governo, a ética e a transparência, reflexo de suas crenças e valores.

Em razão da liderança empresarial que exerce, a Natura é regularmente convocada a debater temas importantes da agenda política nacional: uso sustentável da biodiversidade, política industrial, comércio exterior, desenvolvimento regional, questões regulatórias, inovação tecnológica são alguns dos temas conduzidos pelo Congresso, pelos governos e suas agências, para os quais a Natura busca contribuir.

A Natura relaciona-se com o governo de várias formas e em diversos níveis. Contribui, particularmente, com a discussão de temas específicos do uso sustentável da biodiversidade brasileira, tais como acesso ao patrimônio genético, comércio justo e repartição de benefícios. Essas relações se dão, ora de forma direta, em razão da atuação empresarial, ora indireta, por meio de entidades setoriais às quais a Natura está associada, como a Associação Brasileira de Empresas de Vendas Diretas, ABEVD, e a Associação Brasileira da Indústria de Higiene Pessoal, Perfumaria e Cosméticos, Abihpec. Com essas ações, a empresa busca promover transformações sociais e contribuir para o aumento da competitividade da indústria e do setor, por meio da eliminação de gargalos produtivos, integração da cadeia e incentivos para a promoção de produtos e marcas.

A Natura colabora com diversas organizações da sociedade. Há dez anos, está envolvida com programas para a melhoria da educação pública fundamental. Além disso, 
Comunicação, marketing e responsabilidade social: o caso Natura

de José Américo Tristão, Virgínia Talaveira Valentini Tristão, Elias Frederico e Augustin Rodrigues

apóia e patrocina iniciativas das comunidades do entorno, das comunidades fornecedoras e de organizações da sociedade civil. Como uma das primeiras empresas brasileiras signatárias do Global Compact, a Natura reafirmou, em 2004 e 2005, seu compromisso com os princípios propostos pela Organização das Nações Unidas. Em julho de 2005, foi representada por Guilherme Peirão Leal, co-presidente do Conselho de Administração, no Global Compact's Leaders Forum, em Nova York. Ao longo do ano, realizaram-se diversas ações com o objetivo de disseminar os princípios do Pacto Global e os Objetivos de Desenvolvimento do Milênio para colaboradores, consultoras e parceiros. Por exemplo, as Metas do Milênio foram impressas nas tampas de mais de 860 mil caixas de produtos enviadas para as consultoras em todo o Brasil. Além disso, as metas foram destacadas em diversos materiais de comunicação, como o Vitrine, catálogo de produtos.

Em seus relatórios anuais e balanços sociais publicados no período entre 2001 e 2005, a Natura apresenta seus avanços na promoção dos princípios do Global Compact, com base nos indicadores da Global Reporting Initiative diante dos consumidores e do código de conduta diante dos vendedores diretos e entre empresas da Associação Brasileira de Empresas de Vendas Diretas, ABEVD, elaborados de acordo com modelo proposto pela World Federation of Direct Selling Associations, WFDSA. A empresa respeita, integralmente, o Estatuto da Criança e do Adolescente e segue a Carta de Princípios do Instituto Ethos de Empresas e Responsabilidade Social. Em 2004, tornou-se organisational stakeholder da Global Reporting Initiative, GRI. É a primeira empresa brasileira a fazer parte desse grupo. A Natura é, ainda, reconhecida como: Empresa Amiga da Criança, título outorgado pela Fundação Abrinq pelos Direitos da Criança e do Adolescente; Empresa Cidadã, pela Câmara Municipal de São Paulo; Empresa que Educa, pelo Senac de São Paulo.

\section{CONCLUSÃO}

A partir da análise das informações ligadas ao relacionamento da empresa com seus stakeholders, observa-se que a Natura tem uma atuação orientada ao marketing e para a Responsabilidade Social. Isso é possível por meio da liderança exercida pelos principais executivos da empresa, que, com base nas suas crenças e valores pessoais e em uma rede de relações com entidades sociais, governo, colaboradores e consumidores, tiveram a visão de transformar a Responsabilidade Social em uma estratégia de negócios. A liderança é o aspecto 
Comunicação, marketing e responsabilidade social: o caso Natura

de José Américo Tristão, Virgínia Talaveira Valentini Tristão, Elias Frederico e Augustin Rodrigues

que influencia os valores, as crenças e as atitudes da liderança e constrói a cultura corporativa e o ambiente organizacional para o desenvolvimento da Responsabilidade Social.

A participação ativa da liderança e dos colaboradores da empresa em associações, entidades sociais, cria uma rede de relações sociais e políticas que possibilitam ao líder corporativo captar os movimentos, o cenário, as tendências externas, e trazer para a empresa conhecimento e informações que mobilizam seu desempenho e sua imagem. Além de trazer informações e conhecimento, o líder divulga a atuação da empresa e cunha a imagem e reputação dela no meio empresarial e na sociedade.

A liderança e a divulgação, por meio das ações de marketing social e de documentos como relatórios anuais e balanços sociais, do compromisso da empresa para com o público interno e externo, associadas à definição de políticas para participação nos resultados e filantropia, demonstram a clareza de princípios, valores e crenças da instituição para o público interno. A liderança define a organização, a estratégia e os recursos para o desenvolvimento da Responsabilidade Social, especialmente para a área social: criação de uma área específica de ação social, com recursos humanos, equipe e rede de consultoras, agentes financeiros, porcentagem dos dividendos, além do conhecimento e infra-estrutura para operacionalizar os negócios.

A atuação social da empresa teve efeitos significativos na dinâmica empresarial, destacando-se a satisfação dos empregados e a imagem da empresa para o público externo. De acordo com pesquisas, a Natura é percebida como uma empresa ética, responsável e inovadora, que conseguiu transformar, efetivamente, a Responsabilidade Social em uma oportunidade de negócios e em direção à inovação tecnológica e mercadológica. A empresa criou valor para seus clientes, funcionários e consultores, e estabeleceu uma rede de relacionamentos formais com o conjunto de stakeholders.

\section{REFERÊNCIAS BIBLIOGRÁFICAS}

CARROL, Archie. The pyramid of corporate social responsibility: Toward the moral management of organizational stakeholders business horizons 34, jul/ago 1991.

CORRÊA, S.C.H. Projetos de responsabilidade social: A nova fronteira do marketing na construção da imagem institucional. Dissertação de Mestrado. Rio de Janeiro: COPPEAD/CCJE/UFRJ, 1997. 
Comunicação, marketing e responsabilidade social: o caso Natura

de José Américo Tristão, Virgínia Talaveira Valentini Tristão, Elias Frederico e Augustin Rodrigues

DARROCH, Jenny; MORGAN, P. Miles; JARDINE, Andrew e COOKE, Ernest F. The AMA definition of marketing and its relationship to a market orientation: an extension of Cooke, Rayburn \& Abercrombie, Journal of Marketing Theory and Practice, 12(4), p. 29-38, 2004.

DONALDSON \& PRESTON. The stakeholder theory of the corporation, citing a quote from The Economist, Corporate governance special section, 11 set 1994.

EXAME. As Melhores Empresas para Você Trabalhar. São Paulo: Abril, 2004.

EXAME. As Melhores Empresas para Você Trabalhar. São Paulo: Abril, 2003.

FERNANDES Rubem César. Privado, porém público: o terceiro setor na América Latina. 2. ed. Rio de Janeiro: Relume-Dumará, 1994.

FERREL, O. C. Ética Empresarial: dilemas, tomadas de decisões e casos. Rio de Janeiro: Reichmann \& Affonso, 2001.

FERRELL, O C. et al. Estratégia de marketing. São Paulo: Atlas, 2000.

FRIEDMAN apud MAKOWER, Joel. Beyond the bottom line: putting social responsibility to work for you business and the World. 1999. p. 43.

GUIA EXAME BOA CIDADANIA CORPORATIVA 2005. São Paulo: Abril, 2005.

HANDY, Charles. Para que Serve uma Empresa? Ética e Responsabilidade Social nas Empresas. Trad. Afonso Celso da Cunha Serra. Rio de Janeiro: Elsevier, 2005.

JONES, T.M.; WICKS, A.C. Convergent Stakeholder theory. Academy of Management Review, 1999.

KANITZ, S. A ética resgata a cidadania. Super Varejo, n. 8, set. 2000, p. 12-19.

LEVITT, Theodore. The Dangers of Social Responsibility. Harvard Business Review, sept. 1985.

OLIVEIRA Miguel Darcy de; TANDON, Rajesh. Cidadãos: construindo a sociedade civil planetária. Relatório da Civicus. Versão em português S/i: Prol, 1995.

OLIVEIRA NETO, V. Responsabilidade social exige ética e coerência. Revista Philip Morris. São Paulo: Bandeirantes, abril de 2000.

PAULA, Sérgio Góes \& RODHEN, Patrícia. Filantropia empresarial em discussão: números de concepções a partir do estudo do estudo do Prêmio Eco In: Landim, Leila - org. Ações em Sociedade. Rio de Janeiro: Nau Editora, 1998.

PUPPIM DE OLIVEIRA, J.A. Entendendo as respostas empresariais aos desafios sócioambientais no Brasil: dois estudos de caso. Revista Portuguesa e Brasileira de Gestão, v.1, n. 1, p. 56-70, 2002. 
Comunicação, marketing e responsabilidade social: o caso Natura

de José Américo Tristão, Virgínia Talaveira Valentini Tristão, Elias Frederico e Augustin

Rodrigues

PUPPIM DE OLIVEIRA. Estudos em Desenvolvimento Sustentável e Responsabilidade Socioambiental de Empresa. RAE Eletrônica, v.4, n.1, Art.2, jan/jul.2005.

RELATÓRIO DO SINDICATO DAS INDÚSTRIAS DE PERFUMARIA do Estado de São Paulo, fevereiro, 2005.

RELATÓRIO NATURA 2005. São Paulo: Março, 2006.

SCHOMMER, P.C.; FISCHER, T. Cidadania empresarial no Brasil: Os dilemas conceituais. São Paulo: Peiropolis, v.6, n. 15, mai-ago 1999.

SUCUPIRA, J. A Responsabilidade Social das Empresas. Disponível em: <www.ibase.org.br/páginas/bssucupira.html>. Acesso em: 24 de abril de 2005.

TOMEI, P. A. Responsabilidade social: uma análise qualitativa da opinião do empresariado brasileiro.Dissertação de Mestrado, UERJ, 1981. Trad. Bruno Gaspar Garcia. Responsabilidade Social das Empresas. São Paulo: Peirópolis, 2002.

YIN, Robert K. Estudo de Caso: planejamento e método. Porto Alegre: Bookman, 2005.

Artigo recebido: 04/2012

Artigo aprovado: 06/2012 